\title{
Análise econômica de sistemas de gestão de resíduos sólidos urbanos: o caso da coleta de lixo seletiva em Palmas, TO
}

\author{
Economic analysis of urban's systems of solid waste management: \\ the case of selective garbage collection in Palmas, TO
}

Waldecy Rodrigues ${ }^{[a]}$, Willian Cardoso Santana ${ }^{[b]}$

[a] Pós-doutor em Economia pela Universidade de Brasília (UnB), doutor em Ciências Sociais pela Universidade de Brasília (UnB), professor do Departamento de Economia da Universidade Federal do Tocantins (UFT) e do Programa de Mestrado em Desenvolvimento Regional da Universidade Federal do Tocantins (UFT), Palmas, T0 - Brasil, e-mail: waldecy@terra.com.br

[b] Administrador de empresas, analista em Reforma e Desenvolvimento Agrário do INCRA, mestrando em Ciências do Ambiente pelo Programa de Pós-graduação em Ciências do Ambiente da Universidade Federal do Tocantins (UFT),

Palmas, T0 - Brasil, e-mail: willian.cardososantana@facebook.com

\section{Resumo}

Objetiva-se por esse estudo analisar a viabilidade econômica da implantação de um sistema de coleta de lixo seletiva (SCS) no município de Palmas, Tocantins, considerando as relações entre os custos operacionais do sistema e os benefícios econômicos gerados sob o ponto de vista do contribuinte. Para tanto, utilizou-se do Método de Valoração Contingente (MVC) para estimar os benefícios decorrentes dos serviços prestados a partir da disposição a pagar (DAP) pelos diferentes sistemas de coleta. Além disso, apresentaram-se os custos da coleta convencional e estimaram-se os custos da coleta seletiva. Finalmente, conclui-se que a variação econômica do bem-estar do cidadão não seria compensada na eventual implantação da coleta seletiva na cidade de Palmas. Porém, a decisão sobre a implantação desse sistema deve ter as variáveis econômicas apenas como um dos parâmetros a serem adotados, uma vez que os inúmeros benefícios que a coleta seletiva traz para as gerações atuais e futuras extrapolam a avaliação econômica dos indivíduos sobre seu bem-estar presente.

Palavras-chave: Sistema de coleta de lixo seletiva. Método de valoração. Contingente. Palmas, TO.

\section{Abstract}

This study aims to analyze the economic viability of a selective garbage collection system (SGC) in the city of Palmas, TO. For this purpose, we consider the relationship between the system operational costs and the marginal benefits generated by the SCG from the contributor's standpoint. Thus, we use the Contingent Valuation Method (CVM) to estimate the benefits of services (use value) through the willingness to pay (WTP) for different 
collection systems. In addition, the conventional collection costs were presented and the selective collection costs were estimated. Finally, we conclude that the economic well-being variation is not compensated by the implementation of the SGC in Palmas. However, the decision on the deployment of this system must have the economic variables only as a parameter to be adopted, since the numerous benefits that the selective collection back to the present and future generations, exceeds the economic evaluation of individuals about their present well-being.

Keywords: Selective garbage collection system. Contingent valuation method. Palmas, TO.

\section{Introdução}

Em sua maioria, as cidades usam um sistema tradicional de coleta de resíduos sólidos residenciais, em que há veículos que recolhem os resíduos acondicionados em recipientes abertos ou fechados sem seleção de seu conteúdo. Com o apelo às práticas ambientais politicamente corretas, existe uma tendência (não homogênea entre as localidades) de usar o sistema de coleta seletiva (SCS), no qual os resíduos sólidos são selecionados por categorias. Por esse sistema, assim como no sistema tradicional, os materiais podem ser recolhidos por vários métodos: entrega voluntária pelos munícipes em postos de coleta, recolhimento porta a porta por veículos públicos e contratação de particulares para a captação dos resíduos.

A implantação do sistema é justificada pelas externalidades positivas decorrentes do ganho ambiental gerado pelo aproveitamento dos resíduos recicláveis. Entretanto, há restrições importantes para essa implantação; um deles são os custos orçamentários necessários para a implantação e a manutenção da coleta seletiva. Outra dificuldade é o fato de em muitos municípios não existir uma cultura ambiental forte o bastante para que se promova a implantação do sistema. Em suma, há uma série de circunstâncias que dificultam a implantação e a manutenção da coleta seletiva e que precisam ser confrontados com os benefícios que esse sistema pode gerar.

Em Palmas (TO), o problema não é diferente. A cidade foi fundada em 1989 e ainda está em processo de estruturação. Muitos serviços públicos ainda carecem de ser implantados e outros melhorados. Apesar dos possíveis benefícios advindos da coleta seletiva, sua implantação e manutenção sofrem com a concorrência de demanda por outros serviços que talvez sejam mais prioritários. Um dos grandes problemas de planejamento urbano que a cidade enfrenta é a existência de grandes vazios urbanos, o que encarece substancialmente a prestação de serviços públicos de qualquer natureza, com particular atenção para aqueles relacionados ao urbanismo.

A partir da análise desses problemas e, em especial, do aspecto econômico, emergem os seguintes questionamentos: qual seria a variação econômica no bem-estar dos cidadãos, ocasionada pela adoção do sistema de coleta seletiva? Essa variação de bem-estar seria compensada pela ampliação dos custos com a mudança do sistema tradicional para a coleta seletiva?

Para conseguir responder a essas questões, o objetivo principal desse estudo foi analisar a viabilidade econômica da implantação de um sistema de coleta seletiva no município de Palmas, considerando as relações entre os custos operacionais do sistema e os benefícios marginais gerados sob o ponto de vista do contribuinte.

Este artigo divide-se em quatro seções, além desta introdução. A primeira aborda alguns aspectos teóricos relativos à gestão de resíduos sólidos e sua relação com o desenvolvimento sustentável das cidades, o princípio do poluidor pagador, a provisão de serviços públicos e as formas de valoração dos custos e benefícios ambientais urbanos. 0 segundo trata dos procedimentos para a medição dos benefícios sobre o bem-estar com os sistemas de coleta de resíduos sólidos. 0 terceiro trata dos resultados do trabalho. E o último apresenta as conclusões da pesquisa.

\section{Revisão de literatura}

Gestão de resíduos sólidos e desenvolvimento sustentável nas cidades

Do ponto de vista histórico, principalmente após a Conferência Mundial de Meio e Ambiente e 
Desenvolvimento na cidade do Rio de Janeiro (ECO92), o debate sobre sustentabilidade urbana assumiu maior relevância. Para o atendimento a essa nova demanda, foi estabelecida, também, uma visão contemporânea no trato da consolidação da urbanização com o objetivo de compatibilizar os níveis ambientais de preservação. Os parâmetros para essa nova prática são o uso da gestão de resíduos sólidos, o controle dos efluentes domésticos, a proteção de mananciais, a drenagem e a adequação de infraestrutura em assentamentos.

A cidade consolida o ideal de sustentabilidade urbana à medida que adquire a capacidade de manter o padrão da vida social adequado aos cidadãos, sendo esta condição uma das principais características de harmonização. De maneira geral, parece relativamente simples atingir a condição proposta, mas, na verdade, a aplicação ampla do conceito de sustentabilidade urbana é extremamente complexa e a sua aceitação ainda mais controvertida. A principal fundamentação para a aplicabilidade conceitual da sustentabilidade reside na mudança de comportamento das comunidades locais e nos eventuais ônus econômicos decorrentes de tais mudanças, como o caso de um sistema mais caro de disposição dos resíduos sólidos.

A dinâmica da cidade não absorve a sustentabilidade urbana como um fim absoluto, mas como uma construção, um processo gradativo, com revisão constante das metas e das ações estabelecidas com base nos vetores econômico, social e ambiental. Nesse contexto, um grave problema tratado pela agenda são os dejetos domésticos e industriais despejados nos rios que cortam as cidades. Diariamente são descartados, segundo dados do Ministério do Meio Ambiente (2001), torno de 90 mil toneladas de lixo urbano; $60 \%$ desse montante é recolhido, e desse total somente $25 \%$ é encaminhado para os aterros sanitários. Por estes números, é possível determinar a quantidade de lixo depositado a céu aberto, com um agravante, o país não está preparado para manejo de lixo hospitalar e lixo tóxico.
Sistemas de coleta de resíduos sólidos como serviço público: abordagem microeconômica

A Economia define os serviços públicos como sendo não exclusivos e não rivais. A não exclusividade demonstra a impossibilidade de o usuário expressar a priori suas preferências individuais pelo uso do serviço, ou seja, diferentes indivíduos atribuem satisfações diferenciadas ao uso do mesmo tipo de serviço. Por exemplo, podemos ter dois indivíduos com o mesmo padrão de geração de resíduos sólidos, dos quais apenas um disposto a pagar um valor maior pela implantação de um sistema de coleta seletiva. A não rivalidade se caracteriza pelo fato de que seu uso por um indivíduo não impossibilita o seu uso simultâneo por outros. Desse modo, em regra, o custo marginal ${ }^{1}$ do serviço público tende a zero, uma vez que o acréscimo de um usuário extra pouco ou nada interfere nos custos totais da provisão deste serviço público.

Outro problema relacionado é o fato de que, por suas características, os serviços públicos puros e os semipúblicos tendem a gerar externalidades socialmente desejáveis que não são perfeitamente dimensionadas pelas perspectivas individuais dos usuários. A coleta seletiva é um caso típico de serviço público marcado pela não exclusividade e não rivalidade e com externalidades positivas. Entretanto, ele não pode ser classificado como um serviço público puro já que a não rivalidade ocorre de forma imperfeita, ou seja, à medida que mais usuários utilizam o sistema, maiores são os custos para mantê-lo. A implantação desse sistema exige, portanto, mecanismos de revelação de preferências para que se conheça o bem-estar a ele associado e se compare os custos relativos à sua provisão.

\section{Resíduos sólidos, externalidades ambientais} e o princípio do polvidor pagador

Em Economia, o conceito de externalidade - desenvolvido na década de 1920 pelo economista inglês Arthur Cecil Pigou (1877-1959) - refere-se à

1 Custo marginal é a variação do custo (total ou variável) em função do aumento unitário ou infinitesimal da quantidade. 
ação que um determinado sistema de produção e consumo causa em outros sistemas externos. Pigou defende a existência de uma externalidade quando a produção de uma empresa (ou consumo individual) afeta o processo produtivo ou um padrão de vida de outras empresas ou pessoas, na ausência de uma transação comercial entre elas. Geralmente, estas externalidades não são avaliadas em valores monetários. Elas podem ser tanto negativas quanto positivas. A geração de lixo é um típico exemplo de externalidade ambiental negativa gerada pelas atividades de produção e consumo (FIELD, 1997).

Sempre que existem externalidades a alocação dos recursos não é eficiente. Considere-se um exemplo de um usuário que, diante de um aumento de seus gastos proporcional à poluição produzida por ele, reduzisse seu nível de poluição (a partir da redução de resíduos gerados); isso acarretaria um benefício social bastante grande, mas, infelizmente, não existe um incentivo privado que estimulem comportamentos como esse. No geral, existe uma produção excessiva de resíduos que causa externalidades negativas.

A internalização desses efeitos refere-se às ações, inclusive custos, que se pode tomar no sentido de eliminar as externalidades quando possível, ou, ao menos, reduzi-las para níveis aceitáveis. A internalização também remonta ao estudo pioneiro de Pigou, que lidava com a correção de externalidades negativas mediante a cobrança, pelo Estado, da diferença entre o custo marginal privado e o custo marginal social. A imposição desse ônus ao poluidor tem sido compreendida como um tributo corretivo. 0 Princípio do Poluidor Pagador (PPP), em conformidade com a abordagem pigouviana, induz os agentes poluidores a diminuírem os seus despejos para evitar a cobrança (MAY; LUSTOSA; VINHA, 2003).

Para Streich (2006), externalidades negativas da produção de resíduos sólidos (poluição do solo, das águas, do ar, etc.) indicam falhas do mercado; aqueles que criam o desperdício não internalizam todos os custos associados com suas ações e um nível ineficiente de resíduo acaba sendo gerado. Esse cenário requer, então, a intervenção do governo. Na teoria, os meios mais eficientes de intervenção para conferir um nível mais eficiente à geração de resíduo envolvem a aplicação de uma taxa com valor igual aos danos externos marginais da unidade do resíduo gerado.

\section{Resíduos sólidos e valoração ambiental}

Conforme Randall et al. (1974), os recursos naturais geram diversos bens e serviços que contribuem para o bem-estar geral dos indivíduos. Alguns desses benefícios podem ser valorados por estarem relacionados com o sistema de mercado, como produção de alimentos e minérios. No entanto, outros bens ambientais, por não possuírem preço no mercado, são denominados bens livres ou bens públicos e não possuem valor de troca; alguns desses bens ambientais são a luz do sol, o ar, ou ainda os serviços ambientais proporcionados pela sombra de árvores, a proteção de encostas de morros. Dessa forma, esses recursos comuns de livre acesso e de direitos de propriedade não definidos assumem valores que tendem ao infinito.

Sendo assim, é possível estabelecer valor para os bens e serviços ambientais urbanos e, dessa forma, racionalizar o uso dos recursos naturais? A resposta a essa questão envolve técnicas de valoração econômica do meio ambiente, uma vez que as tradicionais relações de mercado não revelam o valor econômico de bens e serviços ambientais. As técnicas de valoração ambiental foram desenvolvidas com o intuito de suprir a inexistência de mercados apropriados a esses ativos, de forma a fornecer subsídios técnicos para sua exploração racional.

No campo da gestão urbana, o uso dos instrumentos de valoração é relativamente incipiente, porém vários objetos de estudo podem ser delimitados, tais como a medição econômica do bem-estar da arborização urbana, da coleta seletiva e da implantação de unidades de conservação urbanas.

Os métodos de valoração são elaborados para melhor captar o valor econômico total do meio ambiente $^{2}$. Observando a metodologia em uso corrente na economia ambiental, Pearce (1992) explica que

\footnotetext{
2 O valor econômico total (VET) de um recurso ambiental compreende os valores de uso e de não uso (também chamado de valor de existência) de um recurso ambiental. A primeira parcela do VET é composta pelo valor de uso direto, valor de uso indireto, valor de opção e pelo o que Nogueira et. al. (2000) denominam valor de quase opção. 0 valor de não uso equivale ao valor de existência do recurso, ou seja, seu valor intrínseco. No entanto, Pearce e Moran (1995) dividem essa parcela entre valor de legado (bequestvalue) e valor de existência.
} 
existem quatro grandes grupos de técnicas de valoração econômica desenvolvidos em um nível sofisticado. 0 primeiro grupo é formado pelas técnicas denominadas abordagens de mercado convencional, que utilizam os preços de mercado ou preços sombra como aproximação. 0 segundo grupo se refere às funções de produção doméstica (ou familiar). 0 terceiro engloba os métodos de preços hedônicos. E o quarto $\mathrm{e}$ último grupo diz respeito aos métodos experimentais.

Já Hanley e Spash (1993) fazem apenas uma distinção dos métodos de valoração econômica ambiental em dois grupos: (i) forma direta, como o método de valoração contingente (MVC); e (ii) forma indireta, como o método de preços hedônicos (MPH), o método dos custos de viagem (MCV) e as abordagens da função de produção, como o método dos custos evitados (MCE) e o método dose-resposta (MDR). Esses métodos tradicionalmente utilizados em ativos ambientais específicos podem ser apropriadamente aplicados a temas ambientais urbanos, se empregados com cuidado e design metodológicos.

\section{Metodologia}

\section{Método de valoração contingente}

Para avaliar como os contribuintes valorizam os sistemas de coleta e destinação de resíduos sólidos neste trabalho, foi aplicado o Método de Valoração Contingente (MVC). 0 método recebe esse nome porque se propõe a fazer com que as pessoas informem como atuariam em determinadas situações contingentes, isto é, hipotéticas (FIELD, 1997).

O MVC foi aplicado de forma seminal por Davis (1963) para estimar o valor de recursos recreacionais na Floresta de Maine (EUA). Após ser aperfeiçoado por Randall et al. (1974), o método tem crescido em aceitação, tornando-se um instrumento interessante para avaliar bens e serviços que não são provisionados por mercados tradicionais, tipicamente os bens e serviços ambientes e os bens públicos. Para Aguirre e Faria (1996), essa maior aceitação do MVC é consequência de muitas pesquisas no Brasil e no mundo e das tentativas frustradas de desacreditar a metodologia.

Reiterando a pertinência analítica do MVC, Bishop e Herberlein (1979) discutem as limitações do método de avaliação contingente e os possíveis vieses resultantes por meio do cotejo com outros métodos alternativos. Os autores concluem que a avaliação contingente apresenta falhas e deficiências, mas elas não são maiores que as de outros métodos de avaliação indireta; por esse motivo, entende-se que esse tipo de avaliação pode ser utilizado com rigor metodológico.

McFadden (1994) destaca três aspectos que devem ser contemplados na elaboração e avaliação de estudos de valoração contingente. 0 autor adverte, então, que o método deve ser:

a) robusto, no sentido que os resultados não podem ser substancialmente alterados por mudanças no formato da pesquisa, no desenho do questionário e nas instruções, que devem ser imparciais, de modo que o comportamento dos indivíduos seja determinado pela maximização das preferências racionais;

b) estatisticamente confiável, de forma que a distribuição da DAP (Disposição a Pagar) ou da DAR (Disposição a Receber) seja estimada com uma precisão aceitável utilizando-se amostras com tamanhos operacionais;

c) economicamente sensível, de forma que as preferências individuais mensuradas pelo MVC sejam consistentes com os requisitos lógicos de racionalidade (e.g. transitividade) e amplamente consistente com características sensíveis das preferências econômicas (e.g. fração do orçamento do indivíduo que corresponde à sua DAP ou DAR, bem como elasticidade-renda plausíveis).

A estimativa dos benefícios marginais dos sistemas de coleta de resíduos sólidos

Medir modificações sobre o bem-estar em virtude da melhoria de um bem/serviço público ou ambiental é sempre um desafio metodológico, porém com várias respostas no campo das metodologias de valoração econômica. Particularmente, o Método de Valoração Contingente (MVC), quando bem dimensionado em questões de pesquisa relevantes e bem-delimitadas, apresenta-se com uma boa alternativa para medição dos benefícios marginais de determinado ativo ambiental ou bem público sobre o bem-estar dos consumidores (nesse caso contribuintes). Já em relação à estimativa dos custos dos sistemas 
de coleta e tratamento de resíduos sólidos, cabe uma boa escolha da metodologia de custos já amplamente difundida na análise microeconômica.

Para captar as disposições da população a pagar por diferentes sistemas de coleta e destinação de resíduos sólidos urbanos, o MVC foi utilizado, seguido a tendência na valoração de ativos ambientais e serviços públicos, conforme Nogueira e Faria (1998), Martinez-Alier e Jusmet (2001), Motta (1998) e Finco e Valadares (2007).

Neste trabalho, para então captar suas Disposições a Pagar (DAP) pelo uso da coleta seletiva em Palmas, o MVC foi aplicado com o uso de informações de questionários que permitiram revelar as preferências dos contribuintes. $\mathrm{O}$ objeto valorado foi a coleta de resíduos sólidos urbanos (RSU), tal como é prestado atualmente e na forma de coleta seletiva, porta a porta.

Para melhor entendimento do entrevistado sobre cada objeto, foram apresentados o cenário atual dos serviços e um cenário ambientalmente mais favorável, respectivamente. Optou-se pela DAP para medir-se uma variação positiva de disponibilidade. A forma de eliciação do valor foi feita de maneira aberta (open-ended), ou seja, perguntou-se de forma livre qual a disposição a pagar. Esta forma de pergunta produz uma variável contínua de lances e o valor esperado da DAP é obtido pela sua média. Essa forma foi adotada com o objetivo de evitar o viés do ponto inicial, presente em formas de eliciação feitas por lances (bidding games).

Para instrumento de pagamento, manteve-se o meio já utilizado pela Prefeitura de Palmas, que é a Taxa de Remoção de Lixo (TRL), por já ser conhecida e também por ser objeto de estudo. Optou-se por entrevistas domiciliares de forma pessoal. Para obtenção do tamanho da amostra, utilizou-se a técnica de amostragem aleatória simples. A disposição a pagar média estimada com $4 \%$ de erro e $95 \%$ ( $\mathrm{z}=$ $1,96)$ de confiança. 0 tamanho da amostra foi retirado de uma população de 40.435 unidades imobiliárias residenciais edificadas, totalizando uma amostra de 615 unidades com 551 imóveis residenciais e 64 imóveis não residenciais.
Após a coleta e digitação de todos os questionários, com o intuito de conferir consistência aos dados coletados, foram realizados os testes estatísticos como o uso do programa SPSS (Statistical Package for the Social Sciences) para aprimoramento e determinação do modelo econométrico definitivo.

Conforme Motta (1998), no caso de um experimento baseado em eliciação aberta, o valor médio é obtido diretamente com a utilização de técnicas econométricas de regressão para validar o resultado. Uma curva de lances livres pode ser estimada para investigar as determinantes DAP. Normalmente, essa curva correlacionará os lances (DAP) como uma função que engloba o coeficiente linear $\left(Q_{i j}\right)$, a renda $\left(R_{i}\right)$, os fatores sociais como educação $\left(E_{i}\right)$ e outras variáveis explicativas $\left(X_{i}\right)$, sendo que um parâmetro da qualidade ambiental do lugar $\left(A_{j}\right)$ poderia ser incluído, conforme equação a seguir:

$$
D A P_{i}=f\left(Q_{i j^{\prime}} R_{i^{\prime}} E_{i^{\prime}} X_{i^{\prime}} A_{j}\right)
$$

Inicialmente, incluiu-se nos dois modelos (DAP Coleta Seletiva e DAP Coleta Convencional) quatro variáveis que pudessem explicar a disposição a pagar pela coleta seletiva do lixo. Foram incluídas, idade $(I)$, sexo $(S)$, tempo de estudo em anos $(E)$ e renda familiar mensal $(R)$. Para verificação da relação funcional entre a variável aleatória dependente "DAP pela coleta seletiva do lixo" $(Y)$ e essas variáveis independentes, foi adotado o seguinte modelo:

$$
\ln Y i=\beta 0+\beta 1 R i+\beta 2 E i
$$

A partir da mediana (ou média) da DAPM, o valor econômico para cada tipo de coleta, ou seja, a projeção anual foi obtida pela multiplicação destas médias pela quantidade de unidades imobiliárias aptas a receber o serviço de coleta e destinação de lixo, tendo como base os quantitativos atuais, conforme equação a seguir:

$$
\text { DAPTotal }=\text { DAPM * QtdImoveis }
$$

\footnotetext{
3 Este modelo (Log-lin) foi o que melhor se ajustou aos dados e, por isso, foi adotado para análise. Durante a estimação, percebeu-se que apenas as variáveis independentes - renda mensal (R) e tempo de estudo (E) - eram significativos do ponto de vista estatísticos, então se optou por retirar as variáveis sexo (S) e idade (I) do modelo.

${ }^{4}$ Considere-se nessa equação: DAPTotal = Disposição total a pagar; DAPM = Disposição a pagar média; e QtdImoveis = Quantidade de imóveis aptos a receber os serviços.
} 


\section{Levantamento dos custos com a coleta convencional em Palmas e estimativa dos custos da coleta seletiva}

Para o levantamento dos custos atuais com a coleta convencional utilizou-se a pesquisa documental de fontes primárias. Os dados e a fórmula de cálculo para rateio dos custos com a coleta convencional originaram-se da Gerência de Tributação da Secretaria Municipal de Finanças de Palmas. A fórmula fornecida pela prefeitura foi codificada em planilha eletrônica, na qual foram inseridos os dados primários para cálculo. Utilizou-se um percentual de $100 \%$ relativos à recuperação dos custos.

A utilização da mesma fórmula permitiu que os custos fossem rateados entre os diferentes tipos de imóveis para diferentes frequências de coleta, resultando nos valores exatos que cada um teria que pagar caso a totalidade dos custos fosse repassada aos contribuintes. Assim, a fórmula utilizada para cálculo da Taxa de Remoção de Lixo (TRL) foi:

$$
T R L=(P n \times F n \times I C T)
$$

Entenda-se nessa equação: 1 = residencial $3 \mathrm{x}$ por semana; 2 = residencial $6 x$ por semana; 3 = não residencial $3 \mathrm{x}$ por semana; $4=$ não residencial $6 \mathrm{x}$ por semana; 5 = coleta hospitalar; $\mathrm{Pn}=$ Peso atribuído à coleta/tratamento; Fn = Frequência de coleta; e ICT = índice da coleta e do tratamento.

0 índice de coleta e do tratamento é definido como:

$$
I C T=C S /((Q 1 \times P 1 \times F 1)+\ldots(Q n \times P n \times F n))
$$

Leia-se nesta equação: 1 = residencial $3 x$ por semana; 2 = residencial $6 x$ por semana; 3 = não residencial $3 x$ por semana; $4=$ não residencial $6 x$ por semana; 5 = coleta hospitalar; $C S=$ Custo do Serviço; $\mathrm{Qn}=$ Quantidade de coleta; $\mathrm{Pn}=$ Peso atribuído à coleta/tratamento; $\mathrm{Fn}$ = Frequência de coleta; e ICT = índice da coleta e do tratamento.

Para se estimar os custos com a coleta seletiva em Palmas -TO, adotou-se o seguinte procedimento:

$$
\text { CACS }=(\text { GA } \times \text { CTonMes }) \times 12
$$

Entenda-se: CACS $=$ Custo anual com a coleta seletiva (R\$); CTonMes = Custo mensal da coleta seletiva (R\$/t); e GA = Geração Atual de RSU a ser coletado na cidade $(\mathrm{t})$.

0 custo mensal da coleta seletiva foi estimado de acordo com os estudos do CEMPRE (2006) em US\$ 151 por tonelada. Já a estimativa da geração atual de resíduos sólidos urbanos foi realizada de acordo com a proposta metodológica de D'Almeida e Vilhena (2000), e para o município de Palmas foi estimado em 3.150 ton./mês.

\section{Resultados e discussões}

Características econômicas do atual de sistema de coleta de resíduos sólidos em Palmas

Atualmente, o município de Palmas utiliza o sistema convencional de resíduos sólidos. Para arcar com as despesas de coleta e destinação dos mesmos, a cidade utiliza várias fontes de recursos como as receitas provenientes da arrecadação própria do IPTU e Taxa de Serviços Urbanos, entre estas, a Taxa de Remoção de Lixo (TRL) (Tabela 1).

Dentre os serviços de limpeza pública e conservação das vias e logradouros, a coleta e tratamento de RSU representam 35,89\% dos custos totais. Enquanto estes são rateados pela Taxa de Remoção de Lixo (TRL), os demais são rateados pela Taxa de Conservação de Vias e Logradouros (TCL).

As despesas com a coleta de resíduos sólidos urbanos em Palmas em 2009 e que efetivamente foram rateadas em 2010 representaram, aproximadamente, $1 \%$ do orçamento do município. Esse valor pode ser considerado baixo quando comparado com alguns municípios da Região Norte como Manaus $(9,97 \%)$ e Rio Branco $(2,4 \%)$ (ABRELPE, 2008). A partir da pesquisa, pode-se demonstrar a evolução histórica dos custos e do rateio feito pela prefeitura de Palmas (Tabela 2).

Percebe-se que, além de os valores rateados entre os contribuintes usuários dos serviços (a recuperar) serem inferiores aos custos efetivos, existe uma inadimplência média de $63,19 \%$, o que demonstra ineficiência arrecadatória. Outro sinal de ineficiência diz respeito aos valores cobrados individualmente pelos serviços que não acompanharam o aumento dos custos, principalmente entre os exercícios de 2003 e 2004. Enquanto 
Tabela 1 - Custos totais dos serviços de limpeza urbana e conservaç̃ão de vias e logradouros em Palmas em 2010

\begin{tabular}{|c|c|c|}
\hline Serviço & Total (R\$) & (\%) \\
\hline Manutenção de meio-fio e redes de drenagem & $1.342 .365,90$ & 9,65 \\
\hline Tapa-buraco & $1.082 .148,99$ & 7,78 \\
\hline Coleta e tratamento de resíduos sólidos urbanos & $4.992 .873,43$ & 35,89 \\
\hline Varrição de vias e logradouros públicos & $4.560 .317,87$ & 32,78 \\
\hline Remoção de entulho & $29.419,11$ & 0,21 \\
\hline Pintura de meio-fio & $74.344,34$ & 0,53 \\
\hline Coleta de saldo da varriçã̃o & $774.015,60$ & 5,56 \\
\hline Roçagem & $1.056 .695,85$ & 7,60 \\
\hline Total & $13.912 .181,08$ & 100,00 \\
\hline
\end{tabular}

Fonte: Prefeitura Municipal de Palmas, Gerência de Informações Econômicas e Fiscais da Secretaria Municipal de Finanças, 2010.

Tabela 2 - Custos dos serviços de coleta de resíduos sólidos urbanos em Palmas entre 2001 a 2010

\begin{tabular}{rccccc}
\hline Exercíio & Custo Serviços (RS) & A recuperar & $\begin{array}{c}\text { Valores (RS) } \\
\text { Lançado no ano seguinte }\end{array}$ & Arrecadado & $\begin{array}{c}\text { (\%) } \\
\text { Inadimplência }\end{array}$ \\
\hline 2001 & $1.791 .197,22$ & $829.579,44$ & $829.579,44$ & $226.546,18$ & 72,69 \\
2002 & $1.878 .368,00$ & $1.064 .992,28$ & $1.064 .992,28$ & $212.714,99$ & 74,36 \\
2003 & $1.964 .561,00$ & $1.085 .690,23$ & $1.085 .690,23$ & $145.173,42$ & 86,37 \\
2004 & $2.669 .304,99$ & $1.078 .399,22$ & $1.390 .488,41$ & $645.956,19$ & 40,50 \\
2005 & $3.186 .820,03$ & $1.274 .728,01$ & $1.277 .232,44$ & $646.080,82$ & 53,54 \\
2006 & $4.156 .328,56$ & $1.662 .531,42$ & $1.674 .883,65$ & $459.419,32$ & 64,03 \\
2007 & $4.959 .030,30$ & $1.983 .612,12$ & $1.983 .612,12$ & $664.216,16$ & 60,34 \\
2008 & $5.166 .400,00$ & $2.066 .560,00$ & $2.066 .560,00$ & $758.209,00$ & 63,31 \\
2009 & $5.712 .200,00$ & $2.284 .880,00$ & $2.284 .880,00$ & $840.614,00$ & 63,21 \\
2010 & $6.258 .000,00$ & $2.503 .200,00$ & $2.503 .200,00$ & $923.019,00$ & 63,13 \\
\hline
\end{tabular}

Fonte: Prefeitura Municipal de Palmas, Gerência de Informaçōes Econômicas e Fiscais da Secretaria Municipal de Finanças, 2010.

os custos aumentaram aproximadamente $26 \%$, a TRL permaneceu praticamente inalterada. Diante desses dados, surgem novos questionamentos: é possível adotar um sistema mais eficaz de coleta e tratamento de resíduos sólidos? Os custos adicionais são compensadores? A população estaria disposta a pagar por tal incremento de custos?
Avaliação contingente dos serviços de coleta e destinação de resíduos sólidos urbanos em Palmas

O MVC visou avaliar as preferências reveladas dos usuários dos serviços de coleta e destinação de RSU em Palmas, integrantes do mercado real, no 
caso da coleta convencional, e em mercado hipotético, no caso da coleta seletiva.

Com o objetivo de possibilitar a tomada de decisão sobre cada grupo de contribuintes, optou-se por construir modelos diferenciados para cada porção da amostra, uma vez que os valores rateados são distintos entre os imóveis residenciais e os não residenciais. Considerando os usos dos imóveis, os resultados da aplicação dos modelos para o sistema de coleta convencional e seletiva serão detalhados adiante.

A Tabela 3 mostra o caso dos imóveis residenciais e não residenciais para a situação da coleta convencional. No caso dos imóveis residenciais, os resultados deixam claro que a disposição a pagar é mais afetada pela educação do indivíduo do que por sua renda. Assim, um aumento de um ano de escolaridade implica em um aumento de 0,043\% na disposição a pagar pela coleta convencional de resíduos sólidos. Por outro lado, apesar de estatisticamente significativo, o efeito da renda sobre essa disposição foi relativamente próxima a zero.

A Tabela 4 apresenta os resultados para a coleta seletiva.

Observa-se na Tabela 4 que os resultados para a variável renda possuem características bastante semelhantes ao do sistema convencional. O efeito da variável tempo de estudo, que é uma proxy para a educação, mostrou-se próximo aos resultados anteriores, de forma que um ano a mais nos estudos provoca um aumento de aproximadamente $0,05 \%$ sobre a disposição a pagar, conforme as respostas dos contribuintes dos imóveis residenciais.

0 resultado mais destacado ficou por conta do tempo de estudo dos contribuintes dos imóveis não residenciais; observou-se que um ano a mais nos estudos refletem uma disposição a pagar de

Tabela 3 - Modelos para avaliação contingente dos serviços de coleta convencional de resíduos sólidos urbanos em Palmas, 2010

\begin{tabular}{|c|c|c|c|c|c|}
\hline \multicolumn{6}{|c|}{ Imóveis residenciais } \\
\hline Parâmetro & Coeficientes & Erro padrão & Teste $t$ & p-valor & VIF \\
\hline Constante & 2,5190000 & 0,095 & 26,446 & 0,000 & \\
\hline Tempo de estudo em anos & 0,0429537 & 0,010 & 4,347 & 0,000 & 1,252 \\
\hline Renda Familiar mensal & 0,0000314 & 0,000 & 1,930 & 0,054 & 1,252 \\
\hline$R^{2}$ & 0,070 & & & & \\
\hline Durbin-Watson & 0,973 & & & & \\
\hline p-valor & 0,000 & & & & \\
\hline F (calculado) & 18,865 & & & & \\
\hline \multicolumn{6}{|c|}{ Imóveis não residenciais } \\
\hline Parâmetro & Coeficientes & Erro padrão & Teste $t$ & p-valor & VIF \\
\hline Constante & 2,3950000 & 0,368 & 6,507 & 0,000 & \\
\hline Tempo de estudo em anos & 0,0730000 & 0,036 & 2,026 & 0,049 & 1,295 \\
\hline Renda Familiar mensal & 0,0000227 & 0,000 & 0,975 & 0,335 & 1,295 \\
\hline$R^{2}$ & 0,163 & & & & \\
\hline Durbin-Watson & 0,466 & & & & \\
\hline p-valor & 0,017 & & & & \\
\hline F (calculado) & 4,493 & & & & \\
\hline
\end{tabular}

Fonte: Dados da pesquisa. 
$0,10 \%$. Esse valor é maior que a disposição pelo SCS do caso residencial em 0,052 p.p., quase o dobro. Mais ainda, com relação ao caso da coleta convencional (Tabela 3), esse valor é superior às próprias disposições dos contribuintes não residenciais em cerca de 0,029 p.p. e 0,059 p.p., aproximadamente, em relação aos contribuintes de imóveis residenciais.

A partir dos resultados obtidos, estimaram-se as disposições a pagar individual (DAPi) e total (DAPTotal) dos sistemas de coleta convencional e seletiva (Tabela 5). Verificou-se que as disposições do sistema de coleta seletiva são ligeiramente superiores ao da coleta convencional para imóveis residenciais $(18 \%)$ e não residenciais $(3,8 \%)$. Resta questionar se este valor adicional é suficiente para cobrir os custos marginais da implantação do sistema de coleta seletiva.

\section{Estimativas dos custos com os sistemas de coleta}

O custo com os serviços de coleta convencional em 2010 foi de $\mathrm{R} \$ 6.258 .000,00$ para um total de 38.017 imóveis residenciais e 5.102 imóveis não residenciais edificados. Como o município adota a política de recuperação de apenas $40 \%$ dos custos, o montante efetivamente cobrado dos contribuintes residenciais foi de $\mathrm{R} \$ 1.445 .687,27$ e dos não residenciais de $\mathrm{R} \$ 537.924,85$ no exercício fiscal. Se os custos fossem rateados, buscando-se recuperar $100 \%$ do montante despendido, os valores a cobrar seriam $\mathrm{R} \$ 3.666 .467,88$ dos contribuintes residenciais e $\mathrm{R} \$ 1.292 .562,42$ dos não residenciais (Tabela 6).

Baseando-se na estimativa de coleta igual a 3.150 ton./mês ao custo de US\$ $151^{5}$, equivalentes a $\mathrm{R} \$ 254,28$ por tonelada, observou-se que o custo com a coleta seletiva em Palmas seria de R\$ $9.611 .935,20$. Caso esse valor fosse rateado entre os contribuintes, buscando-se recuperar $100 \%$ do montante previsto, os valores a cobrar seriam R\$ 7.106.601,40 dos contribuintes residenciais e $\mathrm{R} \$$ 2.505.333,80 dos não residenciais (Tabela 7).
Análise da viabilidade econômica dos sistemas de coleta de resíduos sólidos

Organizando-se as informações obtidas, pode-se fazer uma análise da viabilidade de manutenção financeira do serviço de coleta e destinação de resíduos sólidos urbanos tal como é realizada atualmente e da viabilidade de manutenção de um SCS em Palmas.

Observou-se que tanto para o sistema de coleta convencional quanto para o sistema de coleta seletiva, as disposições a pagar estão muito abaixo dos custos estimados para a prestação dos serviços. Considerando a DAP como medida do benefício, verifica-se que, para o sistema de coleta convencional, a relação benefício-custo é igual a 0,182, ou seja, os benefícios equivalem apenas a 18,2\% dos custos totais do sistema. Já para a coleta seletiva, a relação benefício-custo é igual a 0,109, ou seja, mesmo apresentando uma DAP superior ao da coleta convencional, esse valor é ainda insuficiente para custear uma possível adoção do SCS (Tabela 8).

Ao distribuir os valores encontrados para os dois sistemas de coleta de resíduos sólidos urbanos, confirma-se que a população de Palmas valora os benefícios bem abaixo dos seus reais custos. No caso da viabilidade da adoção da coleta seletiva, verifica-se que a população estaria disposta a pagar $\mathrm{R} \$ 0,83$ a mais pelo sistema, enquanto os custos marginais por habitante são de $R$ \$ 26,25 (Gráfico 1). Desse modo, somente considerando o ponto de vista econômico, a adoção da coleta seletiva não apresenta viabilidade.

Entretanto, a questão pode ser elaborada de outra forma: o poder público municipal está disposto (e pode) pagar $\mathrm{R} \$ 2,18$ mensais adicionais por habitante para a adoção da coleta seletiva?

De qualquer modo, essa é uma decisão mais política que econômica, porém de relevância para a saúde e longevidade da própria população. Assim, em um cenário de baixa conscientização ou até mesmo desconhecimento da importância do SCS, o poder público pode simplesmente adotar a prática

\footnotetext{
5 Cotação do dólar em 31 mar. 2010: R\$ 1,684. Dólar negociado no câmbio comercial para exportação.
} 
Tabela 4 - Modelos para avaliação contingente dos serviços de coleta seletiva de resíduos sólidos urbanos em Palmas, 2010

\begin{tabular}{|c|c|c|c|c|c|}
\hline \multicolumn{6}{|c|}{ Imóveis residenciais } \\
\hline Parâmetro & Coeficientes & Erro padrão & Teste $\boldsymbol{t}$ & p-valor & VIF \\
\hline Constante & 2,606737 & 0,099 & 26,286 & 0,000 & \\
\hline Tempo de estudo em anos & 0,049947 & 0,010 & 4,850 & 0,000 & 1,245 \\
\hline Renda Familiar mensal & 0,000037 & 0,000 & 2,203 & 0,028 & 1,245 \\
\hline$R^{2}$ & & & 0,089 & & \\
\hline Durbin-Watson & & & 0,830 & & \\
\hline p-valor & & & 0,000 & & \\
\hline F (calculado) & & & 23,555 & & \\
\hline \multicolumn{6}{|c|}{ Imóveis não residenciais } \\
\hline Parâmetro & Coeficientes & Erro padrão & Teste $\boldsymbol{t}$ & p-valor & VIF \\
\hline Constante & 2,1320086 & 0,399 & 5,340 & 0,000 & \\
\hline Tempo de estudo em anos & 0,1017540 & 0,040 & 2,566 & 0,014 & 1,297 \\
\hline Renda Familiar mensal & 0,0000247 & 0,000 & 0,952 & 0,346 & 1,297 \\
\hline$R^{2}$ & & & 0,213 & & \\
\hline Durbin-Watson & & & 0,494 & & \\
\hline p-valor & & & 0,004 & & \\
\hline F (calculado) & & & 6,371 & & \\
\hline
\end{tabular}

Fonte: Dados da pesquisa.

Tabela 5 - Disposiç̃õo a pagar pelos diferentes sistemas de coleta de resíduos sólidos urbanos de Palmas, 2010

\begin{tabular}{|c|c|c|c|c|c|c|}
\hline \multirow{3}{*}{ Sistema de coleta de RSU } & \multicolumn{6}{|c|}{ Uso do Imóvel } \\
\hline & \multicolumn{3}{|c|}{ Residencial } & \multicolumn{3}{|c|}{ Não Residencial } \\
\hline & DAPi (RS) & n. Imóveis & DAPTotal (RS) & DAPi (RS) & n. Imóveis & DAPTotal (RS) \\
\hline Convencional & 20,24 & 38.017 & $769.524,31$ & 25,60 & 5.195 & $132.992,00$ \\
\hline Seletiva & 23,88 & 38.017 & $907.774,80$ & 26,56 & 5.195 & $138.014,19$ \\
\hline $\begin{array}{l}\text { Variação de bem-estar (com } \\
\text { adoç̃ão da coleta seletiva) }\end{array}$ & 3,64 & . & $138.250,49$ & 0,96 & - & $5.022,19$ \\
\hline
\end{tabular}

Fonte: Dados da pesquisa.

Legenda: RSU = Resíduos Sólidos Urbanos; DAPi = disposiçã̃o a pagar individual; DAPTotal = disposiç̃o a pagar total.

mais sustentável de gestão urbana, mesmo que a população não valore a relação entre o serviço prestado e os níveis de bem-estar.

Ademais, a baixa disposição a pagar, tanto pelo sistema convencional quanto por um possível sistema de coleta seletiva, confirma a educação como fator primordial quando o assunto é meio ambiente, pois os indivíduos com maior tempo de estudo se mostraram mais dispostos a investir na qualidade do meio ambiente. 
Tabela 6 - Estimativa dos custos com a coleta convencional em Palmas, 2010

\begin{tabular}{lllllcr}
\hline Uso atual do imóvel/frequência de coleta & Quant. & (P) & (F) & (ICT) & $\begin{array}{c}\text { Valor } \\
\text { TRL }\end{array}$ & $\begin{array}{c}\text { Previsão de } \\
\text { Lançamento (RS) }\end{array}$ \\
\hline Residencial 3x por semana & 37984 & 1 & 3 & 31,66 & 94,99 & $4.553 .016,25$ \\
Residencial 6x por semana & 33 & 1 & 6 & 31,66 & 189,97 & $7.911,20$ \\
Não residencial 3x por semana & 3497 & 2 & 3 & 31,66 & 189,97 & $838.347,61$ \\
Não residencial 6x por semana & 1605 & 2 & 6 & 31,66 & 379,94 & $769.544,13$ \\
Hospitalar & 93 & 4 & 6 & 31,66 & 759,89 & $89.180,81$ \\
Totais & $\mathbf{4 3 . 2 1 2}$ & & & & & $\mathbf{6 . 2 5 8 . 0 0 0 , 0 0}$ \\
\hline
\end{tabular}

Fonte: Dados da pesquisa.

Legenda: $\mathrm{P}$ = peso; $\mathrm{F}$ = frequência; $I C T$ = índice da coleta e do tratamento; TRL = Taxa de Remocão de Lixo.

Tabela 7 - Estimativa dos custos com a coleta seletiva em Palmas, 2010

\begin{tabular}{lcccccc}
\hline $\begin{array}{l}\text { Uso atual do imóvel/frequência } \\
\text { de coleta }\end{array}$ & Quant. & (P) & (F) & (ICT) & $\begin{array}{c}\text { Valor } \\
\text { TRL }\end{array}$ & $\begin{array}{c}\text { Previsão de } \\
\text { Lançamento (RS) }\end{array}$ \\
\hline Residencial 3x por semana & 37984 & 1 & 3 & 61,37 & 184,11 & $6.993 .176,27$ \\
Residencial 6x por semana & 33 & 1 & 6 & 61,37 & 368,22 & $12.151,16$ \\
Não residencial 3x por semana & 3497 & 2 & 3 & 61,37 & 368,22 & $1.287 .654,67$ \\
Não residencial 6x por semana & 1605 & 2 & 6 & 61,37 & 736,43 & $1.181 .976,40$ \\
Hospitalar & 93 & 4 & 6 & 61,37 & $1.472,87$ & $136.976,70$ \\
Totais & $\mathbf{4 3 2 1 2}$ & & & & & $\mathbf{9 . 6 1 1 . 9 3 5 , 2 0}$ \\
\hline
\end{tabular}

Fonte: Dados da pesquisa.

Legenda: $P$ = peso; $F$ = frequência. ICT = índice da coleta e do tratamento; TRL = Taxa de Remocão de Lixo.

Tabela 8 - Benefícios e custos totais dos sistemas de coleta convencional e seletiva de resíduos sólidos em Palmas, 2010

\begin{tabular}{|c|c|c|c|c|c|c|}
\hline \multirow{3}{*}{ Sistema de coleta de RSU } & \multicolumn{4}{|c|}{ Uso atual do imóvel } & \multirow{2}{*}{\multicolumn{2}{|c|}{ Total }} \\
\hline & \multicolumn{2}{|c|}{ Residencial } & \multicolumn{2}{|c|}{ Não Residencial } & & \\
\hline & Custo (R\$) & $\begin{array}{c}\text { DAP (RS) } \\
\text { (Benefício) }\end{array}$ & Custo (R\$) & $\begin{array}{l}\text { DAP (RS) } \\
\text { (Benefício) }\end{array}$ & Custo (RS) & $\begin{array}{l}\text { DAP (RS) } \\
\text { (Benefício) }\end{array}$ \\
\hline Convencional (A) & $3.666 .467,88$ & $769.524,31$ & $1.292 .562,42$ & $132.992,00$ & $4.959 .030,30$ & $902.516,31$ \\
\hline Seletiva (B) & $7.106 .601,40$ & $907.774,80$ & $2.505 .333,80$ & $138.014,19$ & $9.611 .935,20$ & $1.045 .788,99$ \\
\hline Diferença (B - A) & $3.440 .133,52$ & $138.250,49$ & $1.212 .771,38$ & $5.022,19$ & $4.652 .904,90$ & $143.272,68$ \\
\hline
\end{tabular}

Fonte: Dados da pesquisa.

Legenda: RSU = resíduos sólidos urbanos; DAP = disposição a pagar. 
Convencional

Seletiva

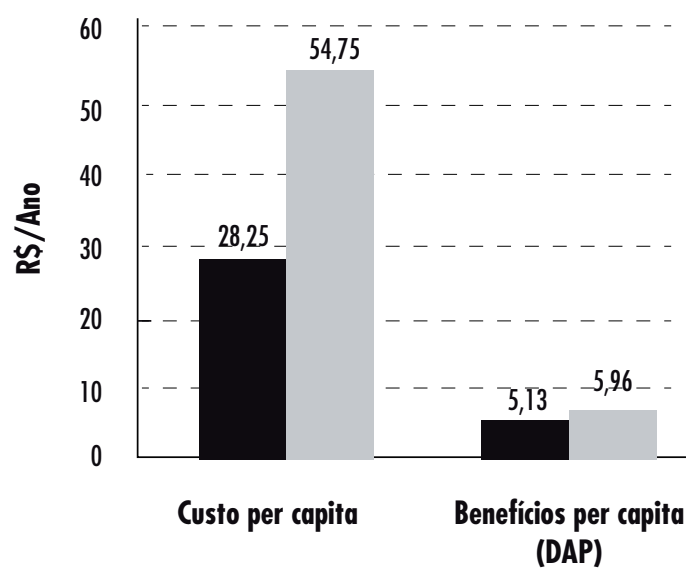

Gráfico 1 - Benefícios e custos per capita dos sistemas de coleta convencional e seletiva de resíduos sólidos em Palmas, 20106

Fonte: Dados da pesquisa.

\section{Conclusão}

O aprimoramento dos sistemas de coleta de resíduos sólidos é imprescindível do ponto de vista da sustentabilidade ambiental, porém um antigo dilema permanece: quem pagará por isso?

No Brasil, segundo o marco regulatório vigente na Política Nacional de Resíduos Sólidos e na Política Nacional de Saneamento, os municípios devem buscar mecanismos gerenciais e econômicos que assegurem a recuperação dos custos dos serviços prestados como forma de garantir sua sustentabilidade operacional e financeira.

Todavia, a realidade se apresenta com várias dificuldades com relação à manutenção e aperfeiçoamento dos sistemas de coleta e tratamento de resíduos sólidos. No caso de Palmas, por exemplo, existe uma grande resistência por parte da população no pagamento da TRL, que segue intuitivamente o princípio do poluidor-pagador. Além de essa taxa cobrir somente $40 \%$ dos custos operacionais do atual sistema de coleta e tratamento, o município convive com elevadas taxas de inadimplência.

Apesar de ser um sistema mais sustentável de coleta e destinação de resíduos sólidos, constatou-se a inviabilidade econômica da adoção do SCS no município de Palmas com base na relação entre os benefícios percebidos pelos contribuintes e os custos adicionais com a implantação do sistema.

No caso da coleta seletiva, a DAP média se mostrou maior que a da coleta convencional; $\mathrm{R} \$ 23,88$ e $R \$ 26,56$ para a coleta em imóveis residenciais e não residenciais respectivamente. Esse resultado evidencia certa disposição dos entrevistados a colaborar com a implantação de um serviço menos agressivo para o meio ambiente. Essa disposição foi demonstrada mais claramente pelos contribuintes com maior renda e principalmente com maior grau de instrução, conforme demonstrou a análise do modelo de regressão. 0 valor anual total, conforme essa disposição a pagar, é de R \$ 1.045.788,99, montante bem inferior aos $\mathrm{R} \$ 9.611 .935,20$ estimados para custear um SCS em Palmas.

Porém, o poder público municipal deve considerar outros fatores na adoção de práticas urbanas mais sustentáveis, desde que suas condições orçamentárias permitam. No caso, a gestão de resíduos sólidos é relevante muito mais como um indicador econômico e ambiental do que como algo que deva determinar a adoção de determinada ação governamental. Assim, é importante que o governo municipal observe os custos marginais da adoção do SCS e também como os contribuintes reagem economicamente com relação à sua DAP. No entanto, a decisão deve levar em conta as diversas externalidades positivas que o SCS pode gerar para as atuais e futuras gerações, que não é de alcance tão imediato das funções de utilidade dos contribuintes.

\section{Referências}

ABRELPE. Panorama dos Resíduos Sólidos no Brasil 2007. São Paulo: ABRELPE, 2008. Disponível em: < http://www.abrelpe.org.br/panorama_apresentacao. cfm>. Acesso em: 1 mar. 2008.

\footnotetext{
${ }^{6}$ Estes dados foram retirados da Tabela 8 e divididos pela população do município de Palmas.
} 
AGUIRRE, A.; FARIA, D. M. C. P. "Avaliação contingente" de investimentos ambientais: um estudo de caso. Estudos Econômicos, v. 26, n. 1, p. 85-109, 1996.

BISHOP, R. C.; HERBERLEIN, T. A. Measuring values of extra market goods: are indirect measured biased? American Journal of Agricultural Economics, v. 61, n. 5, p. 926-930, 1979.

CEMPRE (COMPROMISSO EMPRESARIAL PARA A RECICLAGEM). Pesquisa Ciclosoft, 2006. Disponível em: $<$ http://www.cempre.org.br/ciclosoft_2006.php>. Acesso em: 15 out. 2007.

DAVIS, R. K. The value of outdoor recreation: an economic study of the Maine woods. 1963. $152 \mathrm{f}$. Tese de Doutorado (Departamento de Economia) - Harvard University, Cambridge, 1963.

D'ALMEIDA, M. L. O.; VILHENA, A. (Coord.). Lixo municipal: manual de gerenciamento integrado. São Paulo: IPT; CEMPRE, 2000.

FIELD, B. Environmental economics: an introduction. 3rd ed. New York: McGraw Hill, 1997.

FINCO, M. V. A.; VALADARES, M. B. Valoração econômica: os métodos do custo de viagem e de valoração contingente aplicados às praias de Palmas-TO. 2007. Disponível em: <www.sober.org.br/palestra/6/825.pdf>. Acesso em: 12 jun. 2011.

HANLEY, N.; SPASH, C. L. Cost-Benefit analysis and the environment. Inglaterra: Edward Elgar, 1993.

MARTINEZ-ALIER, J.; JUSMET, J. R. Economia ecológica y política ambiental corregida y aumentada. México: Fondo de Cultura Económica, 2001.

MCFADDEN, D. Contingent valuation and social choice. American Journal of Agricultural Economics, v. 76, n. 4, p. 689-708, nov. 1994.

MAY, P. H.; LUSTOSA, M. C.; VINHA, V. (Org.). Economia do meio ambiente: teoria e prática. Rio de Janeiro: Elsevier, 2003.

MINISTÉRIO DO MEIO AMBIENTE. Plano Nacional de Resíduos Sólidos. Brasília: MMA, 2011.
MOTTA, R. S. Manual para valoração econômica de recursos ambientais. Brasília: Ministério do Meio Ambiente, dos Recursos Hídricos e da Amazônia Legal, 1998.

NOGUEIRA, J. M.; FARIA, R. C. Método de Valoração Contingente: aspectos teóricos e testes empíricos. Caderno de Pesquisas em Desenvolvimento Agrícola e Economia do Meio Ambiente, n. 4, 1998.

NOGUEIRA, J. M.; MEDEIROS, M. A. A.; ARRUDA, F. S. T. Valoração econômica do meio ambiente: ciência ou empiricismo? Cadernos de Ciência e Tecnologia, v. 17, n. 2, p. 81-115, maio/ago. 2000.

PREFEITURA MUNICIPAL DE PALMAS. Gerência de Informações Econômicas e Fiscais da Secretaria Municipal de Finanças, 2010. 1 CD-ROM. (Arquivo texto puro.PALMAS. Agência de Serviços Públicos. ROTAS.XLS: Planilha eletrônica. Palmas, 2010).

PEARCE, D. W. Economic valuation and the natural world. Policy Research Working Paper Series 988. Washington: The World Bank, 1992.

PEARCE, D. W.; MORAN, D. The economic value of biodiversity. Londres: Earthscan Publications, 1995.

RANDALL, A.; IVES, B.; EASTMAN, C. Bidding games for valuation of aesthetic environmental improvements. Journal of Environmental Economics and Management, n. 1, p. 132-149, 1974.

STREICH, F. Incidence analysis of a unit-based garbage tax. Washington DC: Federal Reserve Bank of Minneapolis - Minnesota Economic Association (MEA), 2006. Disponível em: <http://minneapolisfed.org/mea/ papers/streich-2006.pdf >. Acesso em: 15 jan. 2007.

Recebido: 05/02/2012 Received: 02/05/2012

Aprovado: 03/09/2012 Approved: 09/03/2012 